\title{
PERAN PENDIDIKAN KEWARGANEGARAAN DALAM UPAYA MENUMBUHKAN RASA CINTA TANAH AIR
}

\author{
Yudi Firmansyah \\ Program Studi Pendidikan Pancasila dan Kewarganegaraan \\ Fakultas Keguruan dan Ilmu Pendidikan \\ Universitas Buana Perjuangan Karawang \\ yudifirmansyah@ubpkarawang.ac.id
}

\begin{abstract}
The younger generation or the next generation is the generation that will start the results of the struggle of the predecessors by becoming leaders, who can support and advance this nation to become more prosperous and victorious. To make the young generation able to become good leaders who are expected to happen that do not need the love and self-defense of the State that grows in their hearts and souls. The feeling of love to the motherland is very important and must be instilled in the next generation of young people, so that in the future this nation can become a great and victorious nation. This research is a field research, with the type of qualitative descriptive research with the method used is a case study. Citizenship education in this study has an impact on the role of efforts to foster a sense of patriotism for students. The love of the motherland is a thank you and a love for the place of birth or homeland. Helping every successor generation to a large extent be able to apply a sense of love for the land by means of his beik through civic education.
\end{abstract}

Keywords: Citizenship Education, Love the Motherland

\begin{abstract}
Abstrak
Generasi muda atau generasi penerus adalah generasi yang akan meneruskan hasil perjuangan para pendahulu dengan menjadi pemimpin-pemimpin, yang di harapkan dapat merubah dan memajukan bangsa ini menjadi lebih makmur dan berjaya. Untuk menjadikan generasi muda dapat menjadi pemimpin yang baik seperti yang di harapkan tidak akan terjadi apabila tidak rasa cinta dan bela Negara yang tumbuh di hati dan jiwa mereka. Rasa cinta kepada tanah air sangat penting dan harus di tanamkan kepada generasi muda penerus bangsa, agar kedepannya bangsa ini dapat menjadi bangsa yang besar dan Berjaya. Penelitian ini merupakan penelitian lapangan (field research), dengan jenis penelitian deskriptif kualitatif dengan metode yang
\end{abstract}


digunakan yaitu studi kasus. Pendidikan kewarganegaarn dalam penelitian ini mengarhkan kepada peranan dalam upaya menumbuhkan rasa cinta tanah air kepada siswa. Cinta tanah air adalah suatu kasih sayang dan suatu rasa cinta terhadap tempat kelahiran atau tanah airnya. Sehingga setiap generasi penerus bangsa terutama para pelajar mampu untuk mengimplementasikan rasa cinta tanah air dengan sebaik-beiknya melalui pendidikan kewarganegaraan.

Kata kunci : Pendidikan Kewarganegaraan, Cinta Tanah Air

\section{PENDAHULUAN}

Negara Indonesia merupakan bangsa yang memiliki berbagai macam suku, agama, ras, dan potensi di wilayah masing-masing. Banyaknya macam suku di Indonesia menyebabkan perbedaan pendapat dari setiap setia suku dan ras di negara ini. Maka pendidikan kewarganeraan sangat penting dan harus di terapkan di sekolah maupun di lingkungan keluarga, yang bertujuan agar tidak terjadi perpecahan di kemudian hari. Dengan adanya pendidikan kewarganeraan maka generasi penerus akan mengetahui sejarah bangsa. Pengetahuan tentang sejarah bangsa dapat menimbulkan rasa cinta dan bela Negara dalam diri mereka, dan kesatuan persatuan bangsa dapat terjaga. Rasa cinta tanah air yang telah tertanam pada generasi akan meminimalisir resiko terjadi perbedaan pendapat antar suku, ras, dan agama.

Menurut pendapat S. Sumarsono (2002: 6) "Pendidikan Kewarganegaraan adalah usaha untuk membekali peserta didik dengan kemampuan dasar berkenaan dengan hubungan antara warga negara dengan negara serta pendidikan pendahuluan bela negara, agar menjadi warga negara yang dapat diandalkan oleh bangsa dan Negara Kesatuan Republik Indonesia”.

CICED (Center For Indonesian Civic Education) dalam Cholisin (2011:1) mengemukakan bahwa yang dimaksud dengan pendidikan kewarganegaraan adalah :

"Pendidikan Kewarganegaraan merupakan proses transformasi yang membantu membangun masyarakat yang heterogen menjadi satu kesatuan masyarakat Indonesia, mengembangkan warga negara Indonesia yang memiliki pengetahuan dan kepercayaan terhadap Tuhan, memiliki kesadaran yang tinggi terhadap hak dan kewajiban, berkesadaran hukum, memiliki sensitivitas politik, berpartisipasi politik, dan masyarakat madani (Civic Society)"

Pentingnya pendidikan kewarganegaraan dalam menumbuhkan rasa cinta tahan air kepada para siswa merupakan hal yang sangat penting. Mengingat perkembangan generasi muda sejarang yang sangat rentan mendapat pengaruh dari derasnya arus globalisasi.

Menurut Suyadi (2013:9) cinta tanah air merupakan Rasa dan perilaku yang mencerminkan rasa bangga, setia, peduli dan penghargaan yang tinggi terhadap bahasa, budaya, ekonomi, politik dan sebagainya, sehingga tidak akan tergiur dengan tawaran bangsa lain yang dapat merugikan bangsa sendiri. Lebih kongkritnya cinta tanah air adalah suatu perasaan yang timbul dari hati seseorang warga negara untuk mengabdi, memelihara, melindungi tanah airnya dari segala ancaman dan gangguan.

Kurangnya pemahaman siswa tentang sejarah perjuangan bangsa merupakan salah satu faktor yang mempengaruhi Rasa cinta tanah air. Hal ini dapat dilihat dari materi yang disampaikan oleh guru khususnya dalam pembelajaran terlalu sempit serta penyampaian guru yang hanya menekankan pada hasil belajar saja. Sehingga dalam proses pembelajaran peserta didik kurang diberikan 12 pemahaman tentang sejarah perjuangan bangsa yang lambat laun 
akan mempengaruhi lunturnya rasa cinta tanah air siswa. Salah satu cara untuk menumbuhkan rasa cinta tanah air adalah dengan menumbuhkan rasa bangga terhadap tanah air melalaui proses pendidikan di sekolah, akan tetapi bukan hanya sekedar materi mata pelajaran saja atau yang hanya di arahkan pada akademik pelajaran yang mengacu pada kurikulum pemerintah, upaya menumbuhkan rasa cinta tanah air juga dapat dilakukan melalui lagu-lagu nasional dan lagu daerah yang ada di Indonesia.

Rasa bangga terhadap tanah air dapat ditumbuhkan dengan memberikan pengetahuan berbagai nilai-nilai sejarah yang pernah ada, selain itu pesan moral yang ada pada lagu nasional dan lagu daerah dapat menumbuhkan rasa cinta tanah air dari sejak dini yang membuat karakteristik peserta didik menjadi penerus bangsa yang sesuai dengan tujuan pendidikan nasional, yaitu mencerdaskan kehidupan bangsa dan mengembangkan manusia Indonesia seutuhnya yaitu manusia yang beriman dan bertaqwa terhadap Tuhan yang Maha Esa dan berbudi pekerti luhur, memiliki pengetahuan dan ketrampilan, kesehatan jasmani dan rohani, kepribadian dan kemandirian serta tanggung jawab kemasyarakatan dan kebangsaan.

\section{METODE PENELITIAN}

a. Penelitian ini merupakan penelitian lapangan (field research), dengan jenis penelitian deskriptif kualitatif dengan metode yang digunakan yaitu studi kasus. Maksud dari penelitian deskriptif adalah untuk menguraikan literal ihwal manusia, kejadian, atau suatu proses yang diamati (A. Haedar, 2011,26)., yang bertujuan untuk menyederhanakan realitas sosial yang kompleks agar dapat dianalisis, serta bermanfaat untuk menciptakan konsepkonsep ilmiah dan klasifikasi gejala-gejala sosial dalam masalah penelitian.(Judistira K. Gama, 2008, 34.).

b. Penelitian Kualitatif adalah penelitian yang menghasilkan data deskriptif berupa kata-kata yang tertulis, atau kata-kata lisan dari orang-orang dan perilaku yang diamati.(S. Margono, 1997, 36). Data yang akan diperoleh dalam penelitian ini adalah : data observasi, data wawancara/angket, dan data dokumentasi. Model analisis data yang digunakan dalam penelitian ini adalah model interaktif yang dikembangkan oleh Miles dan Huberman yang dimulai dengan pengumpulan data, reduksi data, penyajian data, dan penarikan kesimpulan/verifikasi.( Wahyu, 1996, 61). Proses analisis data dilakukan secara terusmenerus di dalam proses pengumpulan data selama penelitian berlangsung. Pengujian keabsahan data dilakukan dengan menggunakan teknik triangulasi.

c. Penelitian ini dilaksanakan di SMAN I Teluk Jambe Timur Kabupaten Karawang Jawa Barat, dengan waktu penelitian mulai dari bulan Maret 2019 sampai dengan bulan September 2019.

d. Populasi dan sampel Teknik ini dipilih oleh peneliti berdasarkan tujuan penelitian yakni memilih orang-orang yang dapat dijadikan sebagai sampel penelitian karena mereka dianggap dapat memberikan informasi tentang masalah pada penelitian ini. Adapun beberapa informan tersebut adalah: Guru - guru dan pelajar Di SMAN I Teluk Jambe Timur Karawang

\section{PERAN PENDIDIKAN KEWARGANEGARAAN DALAM UPAYA MENUMBUHKAN RASA CINTA TANAH AIR \\ Pengumpulan Data Kuesioner}

Pengumpulan data dilakukan langsung ke siswa dan ke guru yang diambil sebagai sampel dari total polulasi. Dari total yang diambil sampel yaitu 112 orang yang terdiri dari siswa dan guru. 
Semua korespondensi dikerjakan secara bersamaan dan kuesioner langsung dikumpulkan diwaktu yang bersamaan juga, untuk meminimalisir tidak kembalinya kuesioner yang diambil dengan nilai error hanya 5\% seperti yang dapat dilihat pada tabel 4.1 yang menunjukan kesalahan atau error maksimal 5\%. Pengumpulan kuesioner korespondensi dibantu oleh mahasiswa yang Namanya tertera pada penelitian ini, serta dibantu dewan guru yang membantu demi kelancaran prosesnya. Semua pertanyaan yang dihasilkan mengerucut kepada kecintaan pada tana air sehingga dapat dilihat bahwa

\section{Perhitungan Skala Likert}

Berdasarkan jawaban dari respondensi disini akan dibahas 1 per satu poin pertanyaan dan beserta jumlah jawaban yang sudah diberikan oleh responden dengan menggunakan skala likert (Priyono, 2015).

a) Saya mempelajari pelajaran PKn untuk lebih cinta tanah air

$>$ Jawaban responden:

$$
\begin{aligned}
& \mathrm{SS}=51 \\
& \mathrm{~S}=60 \\
& \mathrm{TT}=0 \\
& \mathrm{TS}=1 \\
& \mathrm{STS}=0
\end{aligned}
$$

$>$ Tahap selanjutnya diproses perkalian bobot penilian dengan jumlah jawaban perpoin.

$\mathrm{SS}=51 \times 5=255$

$\mathrm{S} \quad=60 \times 4=240$

TT $=0 \times 3=0$

$\mathrm{TS}=1 \times 2=2$

$\underline{\mathrm{STS}}=0 \times 1=0$

Total Skor $=497$

> Menentukan $(Y)$ dan $(X)$ dengan kata lain menentukan batas atas dan bawah untuk pembagi. Dengan cara mengalihkan total responden dikali dengan nilai bobo terbesar SS (5) dan terkecil STS (1).

$(Y)=$ Total Responden $\times$ Bobot terbesar

$(Y)=112 \times 5=560$

$(X)=$ Total Responden $\times$ Bobot terendah

$(Y)=112 \times 1=112$

$>$ Selanjutnya menghitung rumus indeks persen

Rumus Index $\%=\frac{\text { Total Skor }}{Y} \times 100$

Rumus Index $\%=\frac{497}{560} \times 100=\mathbf{8 8 . 7 5} \%$

Kesimpulan dari hasil ini menunjukan respondensi setuju dengan poin pertanyan P1.

b) PKn merupakan mata pelajaran yang penting untuk dipelajari karena di dalam pelajaran PKn mempelajari tentang hidup bermasyarakat, berbangsa, dan bernegara.

$>$ Jawaban responden :

$$
\begin{aligned}
& \mathrm{SS}=37 \\
& \mathrm{~S}=75 \\
& \mathrm{TT}=0 \\
& \mathrm{TS}=0 \\
& \mathrm{STS}=0
\end{aligned}
$$


Tahap selanjutnya diproses perkalian bobot penilian dengan jumlah jawaban perpoin.

$$
\mathrm{SS}=37 \times 5=185
$$

$\mathrm{S} \quad=75 \times 4=300$

$\mathrm{TT}=0 \times 3=0$

$\mathrm{TS}=0 \times 2=0$

$\underline{\mathrm{STS}}=0 \times 1=0$

Total Skor $=485$

$>$ Menentukan $(Y)$ dan $(X)$ dengan kata lain menentukan batas atas dan bawah untuk pembagi. Dengan cara mengalihkan total responden dikali dengan nilai bobo terbesar SS (5) dan terkecil STS (1).

$(Y)=$ Total Responden $\times$ Bobot terbesar

$(Y)=112 \times 5=560$

$(X)=$ Total Responden $\times$ Bobot terendah

$(Y)=112 \times 1=112$

Selanjutnya menghitung rumus indeks persen

Rumus Index $\%=\frac{\text { Total Skor }}{Y} \times 100$

Rumus Index $\%=\frac{485}{560} \times 100=\mathbf{8 6}, \mathbf{6} \%$

Kesimpulan dari hasil ini menunjukan respondensi setuju dengan poin pertanyan $\mathbf{P 2}$.

c) Dengan belajar PKn saya dapat menjalankan kehidupan bermasyarakat, berbangsa, dan bernegara dengan baik.

Jawaban responden :

$$
\begin{aligned}
& \mathrm{SS}=56 \\
& \mathrm{~S}=52 \\
& \mathrm{TT}=4 \\
& \mathrm{TS}=0 \\
& \mathrm{STS}=0
\end{aligned}
$$

Tahap selanjutnya diproses perkalian bobot penilian dengan jumlah jawaban perpoin.

$\mathrm{SS}=56 \times 5=280$

$\mathrm{S} \quad=52 \times 4=208$

$\mathrm{TT}=4 \times 3=12$

$\mathrm{TS}=0 \times 2=0$

$\underline{\mathrm{STS}=0 \times 1=0}$

Total Skor $=500$

$>$ Menentukan $(Y)$ dan $(X)$ dengan kata lain menentukan batas atas dan bawah untuk pembagi. Dengan cara mengalihkan total responden dikali dengan nilai bobo terbesar SS (5) dan terkecil STS (1).

$(Y)=$ Total Responden $\times$ Bobot terbesar

$(Y)=112 \times 5=560$

$(X)=$ Total Responden $\times$ Bobot terendah

$(Y)=112 \times 1=112$

Selanjutnya menghitung rumus indeks persen 
Rumus Index $\%=\frac{\text { Total Skor }}{Y} \times 100$

Rumus Index $\%=\frac{500}{560} \times 100=\mathbf{8 9}, 2 \%$

Kesimpulan dari hasil ini menunjukan respondensi setuju dengan poin pertanyan $\mathbf{P 3}$.

d) Bagi saya PKn dapat membantu saya memahami hak dan kewajiban saya sebagai warga negara Indonesia.

Jawaban responden :

$$
\begin{aligned}
& \mathrm{SS}=92 \\
& \mathrm{~S}=20 \\
& \mathrm{TT}=0 \\
& \mathrm{TS}=0 \\
& \mathrm{STS}=0
\end{aligned}
$$

$>$ Tahap selanjutnya diproses perkalian bobot penilian dengan jumlah jawaban perpoin.

$\mathrm{SS}=92 \times 5=460$

$\mathrm{S} \quad=20 \times 4=80$

$\mathrm{TT}=0 \times 3=0$

$\mathrm{TS}=0 \times 2=0$

$\underline{\mathrm{STS}=0 \times 1=0}$

Total Skor $=540$

$>$ Menentukan $(Y)$ dan $(X)$ dengan kata lain menentukan batas atas dan bawah untuk pembagi. Dengan cara mengalihkan total responden dikali dengan nilai bobo terbesar SS (5) dan terkecil STS (1).
$(Y)=$ Total Responden $\times$ Bobot terbesar
$(Y)=112 \times 5=560$
$(X)=$ Total Responden $x$ Bobot terendah
$(Y)=112 \times 1=112$

Selanjutnya menghitung rumus indeks persen

Rumus Index $\%=\frac{\text { Total Skor }}{Y} \times 100$

Rumus Index $\%=\frac{540}{560} \times 100=\mathbf{9 6}, \mathbf{4} \%$

Kesimpulan dari hasil ini menunjukan respondensi setuju dengan poin pertanyan P4.

e) Saya belajar PKn supaya memahami pentingnya Pancasila sebagai dasar negara dalam kehidupan berbangsa dan bernegara.

Jawaban responden :

$$
\begin{aligned}
& \mathrm{SS}=93 \\
& \mathrm{~S}=19 \\
& \mathrm{TT}=0 \\
& \mathrm{TS}=0 \\
& \mathrm{STS}=0
\end{aligned}
$$


Tahap selanjutnya diproses perkalian bobot penilian dengan jumlah jawaban perpoin.

$\mathrm{SS}=93 \times 5=465$

$\mathrm{S} \quad=19 \times 4=76$

$\mathrm{TT}=0 \times 3=0$

$\mathrm{TS}=0 \times 2=0$

$\underline{\mathrm{STS}}=0 \times 1=0$

Total Skor $=541$

$>$ Menentukan $(Y)$ dan $(X)$ dengan kata lain menentukan batas atas dan bawah untuk pembagi. Dengan cara mengalihkan total responden dikali dengan nilai bobo terbesar SS (5) dan terkecil STS (1).

$(Y)=$ Total Responden $\times$ Bobot terbesar

$(Y)=112 \times 5=560$

$(X)=$ Total Responden $\times$ Bobot terendah

$(Y)=112 \times 1=112$

Selanjutnya menghitung rumus indeks persen

Rumus Index $\%=\frac{\text { Total Skor }}{Y} \times 100$

Rumus Index $\%=\frac{541}{560} \times 100=\mathbf{9 6 , 6} \%$

Kesimpulan dari hasil ini menunjukan respondensi setuju dengan poin pertanyan $\mathrm{P5}$.

f) Dengan belajar PKn saya dapat mengamalkan nilai-nilai Pancasila yang terkandung di dalamnya seperti menjunjung tinggi persatuan dan kesatuan Indonesia

Jawaban responden :

$$
\begin{aligned}
& \mathrm{SS}=81 \\
& \mathrm{~S}=29 \\
& \mathrm{TT}=0 \\
& \mathrm{TS}=2 \\
& \mathrm{STS}=0
\end{aligned}
$$

Tahap selanjutnya diproses perkalian bobot penilian dengan jumlah jawaban perpoin.

$\mathrm{SS}=82 \times 5=410$

$\mathrm{S}=29 \times 4=116$

$\mathrm{TT}=2 \times 3=6$

$\mathrm{TS}=0 \times 2=0$

$\underline{\mathrm{STS}}=0 \times 1=0$

Total Skor $=532$

Menentukan $(Y)$ dan $(X)$ dengan kata lain menentukan batas atas dan bawah untuk pembagi. Dengan cara mengalihkan total responden dikali dengan nilai bobo terbesar SS (5) dan terkecil STS (1).

$(Y)=$ Total Responden $\times$ Bobot terbesar

$(Y)=112 \times 5=560$ 
$(X)=$ Total Responden $\times$ Bobot terendah

$(Y)=112 \times 1=112$

Selanjutnya menghitung rumus indeks persen

Rumus Index $\%=\frac{\text { Total Skor }}{Y} \times 100$

Rumus Index $\%=\frac{532}{560} \times 100=\mathbf{9 5} \%$

Kesimpulan dari hasil ini menunjukan respondensi setuju dengan poin pertanyan $\mathbf{P 6}$.

g) Karena saya belajar PKn, saya menjadi sadar hukum.

$>$ Jawaban responden:
$\mathrm{SS}=89$
$\mathrm{S}=21$
$\mathrm{TT}=0$
$\mathrm{TS}=2$
$\mathrm{STS}=0$

Tahap selanjutnya diproses perkalian bobot penilian dengan jumlah jawaban perpoin.

$\mathrm{SS}=89 \times 5=445$

$\mathrm{S} \quad=21 \times 4=84$

$\mathrm{TT}=0 \times 3=0$

$\mathrm{TS}=2 \times 2=4$

$\underline{\mathrm{STS}=0 \times 1=0}$

Total Skor $=533$

> Menentukan $(Y)$ dan $(X)$ dengan kata lain menentukan batas atas dan bawah untuk pembagi. Dengan cara mengalihkan total responden dikali dengan nilai bobo terbesar SS (5) dan terkecil STS (1).

$(Y)=$ Total Responden $\times$ Bobot terbesar

$(Y)=112 \times 5=560$

$(X)=$ Total Responden $\times$ Bobot terendah

$(Y)=112 \times 1=112$

Selanjutnya menghitung rumus indeks persen

Rumus Index $\%=\frac{\text { Total Skor }}{Y} \times 100$

Rumus Index $\%=\frac{533}{560} \times 100=\mathbf{9 5}, \mathbf{1} \%$

Kesimpulan dari hasil ini menunjukan respondensi setuju dengan poin pertanyan P7.

h) Dalam materi PKn mengajarkan saya untuk hidup saling bergotongroyong di dalam masyarakat.

$>$ Jawaban responden :

$\mathrm{SS}=80$ 


$$
\begin{aligned}
& \mathrm{S}=29 \\
& \mathrm{TT}=3 \\
& \mathrm{TS}=0 \\
& \mathrm{STS}=0
\end{aligned}
$$

Tahap selanjutnya diproses perkalian bobot penilian dengan jumlah jawaban perpoin.

$$
\mathrm{SS}=80 \times 5=400
$$

$\mathrm{S}=29 \times 4=116$

$\mathrm{TT}=3 \times 3=9$

$\mathrm{TS}=0 \times 2=0$

$\mathrm{STS}=0 \times 1=0$

Total Skor $=525$

$>$ Menentukan $(Y)$ dan $(X)$ dengan kata lain menentukan batas atas dan bawah untuk pembagi. Dengan cara mengalihkan total responden dikali dengan nilai bobo terbesar SS (5) dan terkecil STS (1).

$$
\begin{aligned}
& (Y)=\text { Total Responden } \times \text { Bobot terbesar } \\
& (Y)=112 \times 5=560 \\
& (X)=\text { Total Responden } \times \text { Bobot terendah } \\
& (Y)=112 \times 1=112
\end{aligned}
$$

Selanjutnya menghitung rumus indeks persen

Rumus Index $\%=\frac{\text { Total Skor }}{Y} \times 100$

Rumus Index $\%=\frac{525}{560} \times 100=93,7 \%$

\section{Kesimpulan dari hasil ini menunjukan respondensi setuju dengan poin} pertanyan P8.

i) Mata pelajaran PKn adalah mata pelajaran yang membosankan karena materinya bersifat hafalan saja.

Jawaban responden :

$$
\begin{aligned}
& \mathrm{SS}=37 \\
& \mathrm{~S}=75 \\
& \mathrm{TT}=0 \\
& \mathrm{TS}=0 \\
& \mathrm{STS}=0
\end{aligned}
$$

$>$ Tahap selanjutnya diproses perkalian bobot penilian dengan jumlah jawaban perpoin.

$$
\begin{aligned}
& \mathrm{SS}=37 \times 5=185 \\
& \mathrm{~S}=75 \times 4=300 \\
& \mathrm{TT}=0 \times 3=0 \\
& \mathrm{TS}=0 \times 2=0 \\
& \text { STS }=0 \times 1=0 \\
& \text { Total Skor }=485
\end{aligned}
$$

> Menentukan $(Y)$ dan $(X)$ dengan kata lain menentukan batas atas dan bawah untuk pembagi. Dengan cara mengalihkan total responden dikali dengan nilai bobo terbesar SS (5) dan terkecil STS (1).

$(Y)=$ Total Responden $\times$ Bobot terbesar

$(Y)=112 \times 5=560$ 
$(X)=$ Total Responden $x$ Bobot terendah

$(Y)=112 \times 1=112$

$>$ Selanjutnya menghitung rumus indeks persen

Rumus Index $\%=\frac{\text { Total Skor }}{Y} \times 100$

Rumus Index $\%=\frac{485}{560} \times 100=\mathbf{8 6}, \mathbf{6} \%$

Kesimpulan dari hasil ini menunjukan respondensi setuju dengan poin pertanyan P9.

j) Saya memakai barang produksi asli Indonesia karena saya bangga pada hasil karya Indonesia

Jawaban responden :

$$
\begin{aligned}
& \mathrm{SS}=80 \\
& \mathrm{~S}=30 \\
& \mathrm{TT}=0 \\
& \mathrm{TS}=2 \\
& \mathrm{STS}=0
\end{aligned}
$$

Tahap selanjutnya diproses perkalian bobot penilian dengan jumlah jawaban perpoin.

$$
\begin{aligned}
& \mathrm{SS}=80 \times 5=400 \\
& \mathrm{~S}=30 \times 4=120 \\
& \mathrm{TT}=0 \times 3=0 \\
& \mathrm{TS}=2 \times 2=0 \\
& \text { STS }=0 \times 1=0 \\
& \hline \text { Total Skor }=520
\end{aligned}
$$

Menentukan $(Y)$ dan $(X)$ dengan kata lain menentukan batas atas dan bawah untuk pembagi. Dengan cara mengalihkan total responden dikali dengan nilai bobo terbesar SS (5) dan terkecil STS (1).

$(Y)=$ Total Responden $\times$ Bobot terbesar

$(Y)=112 \times 5=560$

$(X)=$ Total Responden $\times$ Bobot terendah

$(Y)=112 \times 1=112$

Selanjutnya menghitung rumus indeks persen

Rumus Index $\%=\frac{\text { Total Skor }}{Y} \times 100$

Rumus Index $\%=\frac{520}{560} \times 100=\mathbf{9 2 , 8} \%$

Kesimpulan dari hasil ini menunjukan respondensi setuju dengan poin pertanyan $\mathbf{P 1 0}$.

k) Saya selalu mengikuti upacara bendera setiap hari senin.

$>$ Jawaban responden:

$$
\mathrm{SS}=80
$$




$$
\begin{aligned}
& \mathrm{S}=30 \\
& \mathrm{TT}=0 \\
& \mathrm{TS}=2 \\
& \mathrm{STS}=0
\end{aligned}
$$

Tahap selanjutnya diproses perkalian bobot penilian dengan jumlah jawaban perpoin.

$\mathrm{SS}=79 \times 5=395$

$\mathrm{S} \quad=27 \times 4=108$

TT $=5 \times 3=15$

$\mathrm{TS}=0 \times 2=0$

$\underline{\mathrm{STS}}=0 \times 1=0$

Total Skor $=518$

$>$ Menentukan $(Y)$ dan $(X)$ dengan kata lain menentukan batas atas dan bawah untuk pembagi. Dengan cara mengalihkan total responden dikali dengan nilai bobo terbesar SS (5) dan terkecil STS (1).

$(Y)=$ Total Responden $\times$ Bobot terbesar

$(Y)=112 \times 5=560$

$(X)=$ Total Responden $\times$ Bobot terendah

$(Y)=112 \times 1=112$

$>$ Selanjutnya menghitung rumus indeks persen

Rumus Index $\%=\frac{\text { Total Skor }}{Y} \times 100$

Rumus Index $\%=\frac{518}{560} \times 100=\mathbf{9 2 , 5} \%$

Kesimpulan dari hasil ini menunjukan respondensi setuju dengan poin pertanyan P11.

1) Saya mengamalkan pelajaran PKn dalam kehidupan sehari-hari dengan baik seperti bersikap toleransi antar umat beragama.

Jawaban responden :

$$
\begin{aligned}
& \mathrm{SS}=37 \\
& \mathrm{~S}=75 \\
& \mathrm{TT}=0 \\
& \mathrm{TS}=0 \\
& \mathrm{STS}=0
\end{aligned}
$$

$>$ Tahap selanjutnya diproses perkalian bobot penilian dengan jumlah jawaban perpoin.

$$
\begin{aligned}
& \mathrm{SS}=37 \times 5=185 \\
& \mathrm{~S}=75 \times 4=300
\end{aligned}
$$

$\mathrm{TT}=0 \times 3=0$

$\mathrm{TS}=0 \times 2=0$

$$
\underline{\mathrm{STS}=0 \times 1=0}
$$

$$
\text { Total Skor }=485
$$

> Menentukan $(Y)$ dan $(X)$ dengan kata lain menentukan batas atas dan bawah untuk pembagi. Dengan cara mengalihkan total responden dikali dengan nilai bobo terbesar SS (5) dan terkecil STS (1).

$(Y)=$ Total Responden $\times$ Bobot terbesar

$(Y)=112 \times 5=560$ 
$(X)=$ Total Responden $x$ Bobot terendah

$(Y)=112 \times 1=112$

$>$ Selanjutnya menghitung rumus indeks persen

Rumus Index $\%=\frac{\text { Total Skor }}{Y} \times 100$

Rumus Index $\%=\frac{485}{560} \times 100=\mathbf{8 6}, \mathbf{6} \%$

Kesimpulan dari hasil ini menunjukan respondensi setuju dengan poin pertanyan P12.

m) Menegur jika ada yang menggunakan bendera merah putih untuk hal yang tidak benar.

Jawaban responden :

$$
\begin{aligned}
& \mathrm{SS}=101 \\
& \mathrm{~S}=10 \\
& \mathrm{TT}=1 \\
& \mathrm{TS}=0 \\
& \mathrm{STS}=0
\end{aligned}
$$

Tahap selanjutnya diproses perkalian bobot penilian dengan jumlah jawaban perpoin.

$$
\begin{aligned}
& \mathrm{SS}=101 \times 5=505 \\
& \mathrm{~S}=10 \times 4=40 \\
& \mathrm{TT}=1 \times 3=0 \\
& \mathrm{TS}=0 \times 2=0 \\
& \mathrm{STS}=0 \times 1=0 \\
& \text { Total Skor }=545
\end{aligned}
$$

> Menentukan $(Y)$ dan $(X)$ dengan kata lain menentukan batas atas dan bawah untuk pembagi. Dengan cara mengalihkan total responden dikali dengan nilai bobo terbesar SS (5) dan terkecil STS (1).

$(Y)=$ Total Responden $\times$ Bobot terbesar

$(Y)=112 \times 5=560$

$(X)=$ Total Responden $\times$ Bobot terendah

$(Y)=112 \times 1=112$

$>$ Selanjutnya menghitung rumus indeks persen

Rumus Index $\%=\frac{\text { Total Skor }}{Y} \times 100$

Rumus Index $\%=\frac{545}{560} \times 100=97,3 \%$

Kesimpulan dari hasil ini menunjukan respondensi setuju dengan poin pertanyan P13.

n) Melarang mengibarkan bendera merah putih yang sudah robek atau kusam.

$>$ Jawaban responden:

$$
\begin{aligned}
& \mathrm{SS}=103 \\
& \mathrm{~S}=9 \\
& \mathrm{TT}=0 \\
& \mathrm{TS}=0 \\
& \mathrm{STS}=0
\end{aligned}
$$


Tahap selanjutnya diproses perkalian bobot penilian dengan jumlah jawaban perpoin.

$\mathrm{SS}=103 \times 5=515$

$\mathrm{S}=9 \times 4=36$

$\mathrm{TT}=0 \times 3=0$

$\mathrm{TS}=0 \times 2=0$

$\underline{\mathrm{STS}=0 \times 1=0}$

Total Skor $=551$

> Menentukan $(Y)$ dan $(X)$ dengan kata lain menentukan batas atas dan bawah untuk pembagi. Dengan cara mengalihkan total responden dikali dengan nilai bobo terbesar SS (5) dan terkecil STS (1).

$(Y)=$ Total Responden $\times$ Bobot terbesar

$(Y)=112 \times 5=560$

$(X)=$ Total Responden $\times$ Bobot terendah

$(Y)=112 \times 1=112$

Selanjutnya menghitung rumus indeks persen

Rumus Index $\%=\frac{\text { Total Skor }}{Y} \times 100$

Rumus Index $\%=\frac{551}{560} \times 100=\mathbf{9 8}, \mathbf{3} \%$

Kesimpulan dari hasil ini menunjukan respondensi setuju dengan poin pertanyan P14.

o) Mendahulukan keperluan negara dari kepentingan pribadi

$>$ Jawaban responden:

$$
\begin{aligned}
& \mathrm{SS}=70 \\
& \mathrm{~S}=40 \\
& \mathrm{TT}=2 \\
& \mathrm{TS}=0 \\
& \mathrm{STS}=0
\end{aligned}
$$

$>$ Tahap selanjutnya diproses perkalian bobot penilian dengan jumlah jawaban perpoin.

$\mathrm{SS}=70 \times 5=350$

$\mathrm{S} \quad=40 \times 4=160$

$\mathrm{TT}=2 \times 3=6$

$\mathrm{TS}=0 \times 2=0$

$\underline{\mathrm{STS}=0 \times 1=0}$

Total Skor $=516$

Menentukan $(Y)$ dan $(X)$ dengan kata lain menentukan batas atas dan bawah untuk pembagi. Dengan cara mengalihkan total responden dikali dengan nilai bobo terbesar SS (5) dan terkecil STS (1).

$(Y)=$ Total Responden $\times$ Bobot terbesar

$(Y)=112 \times 5=560$

$(X)=$ Total Responden $\times$ Bobot terendah

$(Y)=112 \times 1=112$

Selanjutnya menghitung rumus indeks persen 
Rumus Index $\%=\frac{\text { Total Skor }}{Y} \times 100$

Rumus Index $\%=\frac{516}{560} \times 100=\mathbf{9 2 , 1} \%$

Kesimpulan dari hasil ini menunjukan respondensi setuju dengan poin pertanyan $\mathbf{P 1 5}$.

\section{KESIMPULAN}

Penelitian ini mendapati pelajaran PPKn pada siswa SMA yang pada penelitian ini diambil kelas 12 IPS bahwa pendidikan kewarganegaraan mempunyai pengaruh yang positif terhadap upaya menumbuhkan rasa cinta tanah kepada para siswa

\section{DAFTAR PURTAKA}

A. Chaedar Alwasilah. (2011). Linguistik Suatu Pengantar. Bandung: Angkasa.

Cholisin. 2011. Pengembangan Karakter Dalam Materi Pembelajaran PKn. Makalah disampaikan pada kegiatan MGMP PKn SMP Kota Yogyakarta.

Judistira, K, 2008, Dasar dan Proses Penelitian Sosial, Bandung; Primaco Akademika.

Margono, S., 1997 Metodologi Penelitian Pendidika,Jakarta: Renika Cipta.

Priyono, A. (2015). Metode Perhitungan Service Level Agreement (SLA) dan Persepsi User Terhadap Kemudahan Akses Layanan Informasi BKIPM. Kementrian Kelautan Dan Perikanan, 7.

Sumarsono dkk. (2002). Pendidikan Kewarganeggaraan. Jakarta: PT Gramedia Pustaka Utama. Suyadi. 2013. Strategi Pembelajaran Pendidikan Karakter. Bandung: PT. Remaja Rosdakarya. Wahyu, 1996, Pedoman Penelitian Pendidikan, Bandung: Tarsito. 